\title{
Prevalence of Chlamydia trachomatis in women attending a family planning clinic in Papua New Guinea
}

J J H Theunissen, G Kariwiga, J M Ossewaarde, J H van Rijsoort-Vos, E Stolz, W I van der Meijden

\begin{abstract}
Objective-To determine the prevalence of Chlamydia trachomatis infection in women attending a family planning clinic in Papua New Guinea, in the period between April and June 1991.

Setting-The outpatient department of Obstetrics and Gynaecology of Port Moresby General Hospital, Port Moresby, Papua New Guinea, the departments of Dermato-Venereology and Clinical Microbiology of the Erasmus University, Rotterdam, The Netherlands and the National Institute of Public Health and Environmental Protection, Bilthoven, The Netherlands.
\end{abstract}

Patients-A total of 254 consecutive women who attended the family planning clinic at Port Moresby General Hospital, Papua New Guinea were enrolled into this study.

Methods-Cervical infections with $\boldsymbol{C}$ trachomatis were diagnosed using the direct immunofluorescent assay (DFA) and the polymerase chain reaction (PCR). Serum IgM and IgG antibodies directed against $C$ trachomatis were detected using the enzyme-linked fluorescent assay (ELFA). Results-The prevalence of $C$ trachomatis was $14 \cdot 6 \%$ using the PCR, $9.1 \%$ using the DFA and $17 \cdot 3 \%$ when the results of the PCR and the DFA were combined. An elevated IgM titre was observed in $14 \cdot 2 \%$ of the women, whereas $44 \cdot 1 \%$ had an elevated IgG titre. The titres of IgM or IgG were significantly higher in women who were positive using the PCR or the DFA than in those who were negative in both the PCR and the DFA $(p=0.032$ and $p=0.0046$, respectively).

Conclusion-Cervical infection by $C$ trachomatis can be considered a major health problem in at least the studied population in Papua New Guinea. The prevalence of $\boldsymbol{C}$ trachomatis infection is at least comparable with that in groups with a high prevalence in industrialized countries. Effective screening and treatment programmes are imperative to combat this problem.

(Genitourin Med 1995;71:295-298)

Keywords: Chlamydia trachomatis; Family planning; Papua New Guinea

Introduction

Sexually transmitted diseases (STDs) such as gonorrhoea, syphilis and infections with chlamydiae are a major health problem in developing countries ${ }^{1}$. In contrast to what is observed in industrialised countries, the prevalence of STDs in developing countries appears to be increasing. ${ }^{1}$

The prevalence of genital Chlamydia trachomatis infections in the USA, in a college student population, was approximately $5 \%{ }^{2}$ In developing countries, the prevalence varies per individual country and within each population. It is observed to vary from $6.3 \%$ in women attending a Kenyan family planning clinic $^{3}$ to $44 \%$ in pregnant women in $\mathrm{El}$ Salvador. ${ }^{4}$ The frequent occurrence of complications (such as pelvic inflammatory disease and neonatal conjunctivitis) as a direct consequence of this high prevalence is a major health problem in developing countries.

In Papua New Guinea, $17 \cdot 7 \%$ of the women who at an antenatal clinic were found to be infected with $C$ trachomatis. ${ }^{5}$ In our study, the prevalence of genital $C$ trachomatis infections was investigated in women attending the family planning clinic at Port Moresby General Hospital, Port Moresby, Papua New Guinea. The polymerase chain reaction (PCR) and the direct fluorescent assay (DFA) were used to establish current infections. At the same time, IgM and IgG antibody titres were determined in order to obtain information about the spread of $C$ trachomatis infection.

\section{Materials and methods}

Patients The patient group consisted of 254 women who lived in the National Capital District in Papua New Guinea. The age range was 17 to 43 years (mean 25). More than $85 \%$ of the women were married. Approximately $30 \%$ of the study population did not have any form of formal education. All women visited the outpatient Department of Obstetrics and Gynaecology of Port Moresby General Hospital, between April and June 1991. Cervical swabs were obtained from all patients to establish the presence of $C$ trachomatis using culture. Owing to import problems, however, the swab samples were thawed and we decided to perform PCR rather than culture. At the same visit also cervical smears were obtained for DFA and a blood sample was taken from each patient to determine IgM and IgG antibody titres against $C$ trachomatis. After drying, smears intended for DFA, were fixed. At the end of the study, the swabs, fixed smears and blood samples were sent by air mail to the departments of Dermato-Venereology and Clinical 
Microbiology, University Hospital Dijkzigt and Erasmus University Rotterdam and to the National Institute of Public Health and Environmental Protection (RIVM) in Bilthoven, for further processing.

Cultures to determine the presence of $N$ gonorrhoeae in the cervix were not performed because the appropriate culture media were, at that time, not available at the laboratory of Port Moresby General Hospital.

Polymerase Chain Reaction (PCR) Swabs for detecting $C$ trachomatis using the PCR were frozen at $-70^{\circ} \mathrm{C}$ in $1.5 \mathrm{ml} 20 \mathrm{mM}$ phosphate buffer containing $0.2 \mathrm{M}$ sucrose (Merck, Darmstadt, Germany), $49 \mathrm{mM}$ glutamine (Sigma, St. Louis, MO, USA), 10\% FCS, $18 \mu \mathrm{g} / \mathrm{ml}$ gentamicin, $23 \mu \mathrm{g} / \mathrm{ml}$ vancomycin and $2.5 \mu \mathrm{g} / \mathrm{ml}$ amphotericin B (SPG). The PCR was performed according to the method described by Claas et al. ${ }^{6}$ DNA was extracted from $0.5 \mathrm{ml}$ of the sample from each patient. Two sets of oligonucleotide primers were used. The first set $(R 1=$ GTGGATAGTCT CAACCCTAT, R2 = TATCTGTCCTTGCGGAAAAC), was derived from $16 \mathrm{~S}$ rRNA gene sequences of $C$ psittaci ${ }^{7}$ and generated a 208-bp amplified product with all four Chlamydia species. The second set (T1 = GGACAAATCGTATCTCGG, T2 = GAAACCAACTCTACGCTG) was derived from sequences of the common endogenous plasmid of $C$ trachomatis ${ }^{8}$ and generated a 517-bp product with all known $C$ trachomatis serovars. After 40 cycles, the amplification product was analysed on a $2 \%$ agarose gel.

Direct immunofluorescent assay (DFA) C trachomatis elementary bodies (EBs) were detected using the DFA as follows. In the Port Moresby General Hospital, a smear of the sample from the cervix was prepared on a glass slide. After drying, it was fixed in methanol. After postage to the National Institute of Public Health and Environmental Protection, the preparation was then stained with FITC-conjugated anti $C$ trachomatis monoclonal antibody (Microtrak, Syva Co., Palo Alto, Calf.) and examined at a magnification of $\times 500$ using a fluorescent microscope. The presence of 5 or more EBs was regarded as positive.

Enzyme-Linked Fluorescent Assay (ELFA) Specific IgM and IgG antibodies to $C$ trachomatis were determined according to the method described previously. ${ }^{9}$ Wells of PVC microtitre plates were coated with $50 \mu \mathrm{l}$ of a $10 \mu \mathrm{g} / \mathrm{ml}$ elementary bodies (EB) suspension of the $C$ trachomatis serotypes $\mathrm{E}$ (strain UW-5/cx), F (strain IC-Cal3), H (strain UW4/Cx), I (strain UW-12/Ur), J (strain UW$36 / \mathrm{Cx}$ ) and LGV2 (strain $343 / \mathrm{Bu}$ ) in $0.1 \mathrm{M}$

Prevalence of Chlamydia trachomatis as measured by the polymerase chain reaction (PCR) and/or the direct immunofluorescent assay (DFA)

\begin{tabular}{llll}
\hline Detection method & Positive patients & Negative patients & Prevalence (\%) \\
\hline PCR & 37 & 217 & $14 \cdot 6$ \\
DFA & 23 & 231 & $9 \cdot 1$ \\
PCR and DFA & 16 & 238 & $6 \cdot 3$ \\
PCR or DFA & 44 & 210 & $17 \cdot 3$ \\
\hline
\end{tabular}

carbonate/bicarbonate buffer ( $\mathrm{pH} 9 \cdot 6)$. After incubation at $4^{\circ} \mathrm{C}$ for $16 \mathrm{~h}$, the unoccupied binding-sites were blocked with PBS containing $2 \%$ BSA. The plates were subsequently rinsed with $\mathrm{PBS}$ containing $1 \% \mathrm{BSA}$ and $0.05 \%$ Tween-20 (PBST) and incubated with $50 \mu$ diluted test serum (1:250 for IgM determination and 1:1000 for IgG determination) at $22^{\circ} \mathrm{C}$ for $45 \mathrm{~min}$. The plates were then rinsed with PBST and incubated at $22^{\circ} \mathrm{C}$ for $45 \mathrm{~min}$ with either $50 \mu \mathrm{l}$ of $1: 8000$ dilution of anti-human IgG biotin (Boehringer, Mannheim, Germany) or with $50 \mu$ l of 1:20 dilution of anti-human IgM which had been coupled to $\beta$-galactosidase. The plates were then rinsed with PBST and those for IgG titre determination incubated for a further $45 \mathrm{~min}$ at $22^{\circ} \mathrm{C}$ after addition of $50 \mu \mathrm{l}$ of $1: 4000$ dilution of streptavidin $\beta$-galactosidase (Boehringer) and subsequently rinsed with PBST. The final step consisted of a $1 \mathrm{~h}$ incubation at $37^{\circ} \mathrm{C}$ with $100 \mu \mathrm{l}$ of $0.25 \mathrm{mg} / \mathrm{ml}$ 4-methylumbelliferyl $\beta$-D-galactoside (Sigma, St. Louis, MO, USA) in a buffer containing $44 \mathrm{mM} \mathrm{K} \mathrm{HPO}_{4}, 55 \mathrm{mM} \mathrm{K \textrm {K } _ { 2 }} \mathrm{PO}_{4}, 4 \mathrm{mM}$ $\mathrm{MgCl}_{2}$ (pH 7·6). The reaction was stopped by adding $100 \mu \mathrm{l}$ of $1 \mathrm{M} \mathrm{Na}_{2} \mathrm{CO}_{3}$. Fluorescence was measured at $480 \mathrm{~nm}$ using Fluoroscan 1 (Flow Laboratory, Irvine, Scotland). The negative cut-off points for IgG and IgM were determined as described previously. ${ }^{9}$

Statistical analysis Statistical significance $(p<0.05)$ was calculated using the Fisher exact test.

\section{Results}

While only $12 \%$ of the women were complaining about vaginal discharge, vaginal infection was diagnosed in considerably more women. Bacterial vaginosis and trichomoniasis were especially prevalent (25 and $22 \%$ respectively). We did not find an association between gynaecological complaints (namely abdominal pain and/or vaginal discharge) and the presense of $C$ trachomatis infection.

The prevalence of cervical $C$ trachomatis infections determined using PCR and DFA is shown in the table. The number of patients who were positive using PCR as the method for detection did not differ significantly from the number who were positive using DFA $(p=0.073)$. Although the majority of patients who were positive using DFA were also positive using PCR (69.6\%), the overlap was not large enough to justify the use of the PCR as the sole method for detection.

Increased IgM titres $(\geqslant 1 / 250)$ were observed in the sera of $36(14 \cdot 2 \%)$ patients. In 10 of these 36 IgM positive patients, cervical $C$ trachomatis infection was established using PCR, whereas 26 patients were negative using PCR. There were significantly more patients with an increased IgM titre in the PCR-positive group than in the PCR-negative group ( $p=0.014)$. The majority of the patients who were positive using PCR and DFA had an increased IgM titre as compared with those who were negative using PCR and DFA $(p=0.036)$. This difference was not sig- 
nificant when comparing IgM titres and results of DFA only $(p=0 \cdot 11)$.

Increased IgG $(\geqslant 1 / 1000)$ titres were observed in the sera of $112(44 \cdot 1 \%)$ patients. In 26 of these 112 patients, cervical $C$ trachomatis infection was established using PCR, whereas 86 patients who had an increased IgG titre were negative using PCR. The IgG titres were significantly higher in the PCRpositive group than in the PCR-negative group ( $p=0.0006)$. The number of patients with an increased IgG titre in the PCR- and the DFA-positive group was higher than that in the PCR- and the DFA-negative group $(p=0.0046)$. This difference was not statistically significant when comparing IgG titres and results of DFA only $(p=0 \cdot 27)$.

\section{Discussion}

In this study, using PCR and DFA, a cervical $C$ trachomatis infection was established in respectively $14.6 \%$ and $9 \cdot 1 \%$ of the women who attended the family planning clinic of Port Moresby General Hospital. Since there is a good correlation between the results of tissue culture and that of $\mathrm{PCR}^{6}$ and since there was a somewhat less agreement between DFA and tissue culture, ${ }^{10}$ the prevalence observed using PCR appeared to be more reliable. Since only $69.9 \%$ of the patients who were positive using DFA were also positive using PCR, in this patient group it appeared to be insufficient to use only PCR for reliable diagnostics. In part these discordant results of PCR and DFA can be explained by assuming a rather low number of elementary bodies in some of the patients. Because transport of swabs and smears was delayed owing to administrative problems, the transport medium in the swab-containing tubes was thawed on arrival. This certainly has had adverse effects on PCR sensitivity. Because DFA smears were fixed prior to transport, sensitivity of DFA was not, or was considerably less, affected by the transport delay. So in our opinion the positive results of both PCR and DFA, for reasons described above, should be combined to give the best estimation of the extent of urogenital $C$ trachomatis infection in the study population, altogether being $17 \cdot 3 \%$. This corroborated the prevalence that was observed previously, using DFA as the method for detecting $C$ trachomatis in a group of pregnant women in Papua New Guinea. ${ }^{5}$ Such high prevalences of genital $C$ trachomatis infections have also been reported from other developing countries ${ }^{11-13}$. Owing to limited resources, however, PCR as well as DFA or culture are not suitable for screening purposes in developing countries. Relatively cheap tests that give results within a hour are theoretically more suitable for use in developing countries. Because of the often low sensitivity of such tests, if compared with culture, ${ }^{14}$ further research is needed, before use in developing countries can be advocated.

The composition of the patient group studied was comparable with that of a sexually active female population aged between 15 and
40 years in the industrialised world. The prevalence of $\operatorname{IgM}(14 \cdot 2 \%)$ and $\operatorname{IgG}(44 \cdot 1 \%)$ antibodies against $C$ trachomatis in the patient group studied was identical to that in a group of patients with a high prevalence of $C$ trachomatis infections in the western world. ${ }^{915}$ Using the combination of PCR and DFA results as the best estimation of the amount of urogenital $C$ trachomatis infections in the population studied, the sensitivity and the specificity of an increased titre of IgM antibodies against $C$ trachomatis were observed to be $25.0 \%$ and $88.1 \%$ respectively. Similarly, the sensitivity and the specificity of an increased IgG titre were observed to be $63.6 \%$ and $60.0 \%$ respectively. Similar figures were also previously reported from Rotterdam in a group of women with a high prevalence of $C$ trachomatis antibodies 9 .

Logistically, it was not possible to determine sero-conversions in the group of patients in Papua New Guinea. As a direct consequence and because of the observation that IgG antibodies can be demonstrated in serum for many years, ${ }^{16}$ the detection of IgM and/or IgG antibodies against $C$ trachomatis was unsuitable for establishing acute infections. Also, trachoma is endemic in Papa New Guinea. Because $C$ trachomatis serovars causing trachoma and urogenital infections are indistinguishable in the serological test used, the percentage of the population with an increased titre of IgG antibodies against $C$ trachomatis is only useful as an epidemiological indicator of the extent to which $C$ trachomatis had spread in the population. As such, it was established that approximately half of the women studied had previously been in contact with $C$ trachomatis.

It is concluded that cervical $C$ trachomatis infections are widespread in Papua New Guinea and that there is a definite need for screening women who visit secondary and tertiary health care facilities, especially those of childbearing age.

Part of the diagnostic material was supplied through a grant of the European Community (AIDS Task Force, Brussels, Belgium).

Dr B Tank is thanked for correcting the English text.

1 World Health Organisation Expert Committee on Venereal Diseases and Treponematoses. Tech Rep Ser 1986 ;No.736

2 McCormack WM. Infection with Chlamydia trachomatis in women college students. In: Mårdh $\mathrm{PA}$, Holmes $\mathrm{KK}$, Oriel JD, Piot P, Schachter J eds. Chlamydial Infections Vol. 2. Amsterdam: Elsevier Biomedical Press, 1982: 151-4.

3 Engels $H$, Nyongo A, Temmerman $M$, Quint WG, Van Marck E, Eylenbosch WG. Cervical cancer screening and detection of genital HPV-infection and chlamydia infection in different groups of Kenyan women. Ann Soc Belg Med Trop 1992;72:53-62.

4 Posada AB, Jonasson J, de Linares L, Bygdeman S. Prevalence of urogenital Chlamydia trachomatis infection in El Salvador. 1. Infection during pregnancy and perinatal transmission. Int F STD AIDS 1992;3:33-7.

5 Klufio CA, Amoa AB, Delamare O, Kariwiga G. Endocervical Chlamydia trachomatis infection in preg nancy: direct test and clinico-sociodemografic survey of nancy: direct test and clinico-sociodemografic survey of pregnant patients at the Port Moresby Hospital antenatal $f$ Obstet Gymaecol $1992 \cdot 32: 43-6$.

6 Claas HJC, Wagenvoort JHT, Niesters HGM, Tio TT, Van Rijsoort-Vos JH, Quint WGV. Diagnostic value of the polymerase chain reaction for Chlamydia as deter- 
mined in a follow-up study. 7 Clin Microbiol 1991;29: 42-5.

7 Wiesburg WG, Hatch TP, Woese CR Eubacterial origin of chlamydiae. F Bacteriol 1986;167:570-4.

8 Sriprakash KS, Macavoy ES. Characterisation and sequence of a plasmid from the trachoma biovar of Chlamydia trachomatis. Plasmid 1987;18:205-14.

9 Theunissen JIH Van Heijst BYM, Chin-A-Lien RAM Wagenvoort JHT, Stolz E, Michel MF. Detection of antibodies in patients with uncomplicated Chlamydia trachomatis infection: a comparison between enzyme linked fluorescent assay and isolation in cell culture. Int $\mathcal{F}$ STD AIDS 1993;4:43-8.

10 Barnes RC. Laboratory diagnosis of human Chlamydial infections. Clin Microbiol Rev 1989;2:119-36.

11 Somji S, Kazmi SU, Sultana A. Prevalence of Chlamydia trachomatis infections in Karachi, Pakistan. fpn $\mathcal{F}$ Med Sci Biol 1991;44:239-43.
12 Ismail SO, Ahmed HJ, Jama MA et al. Syphilis, gonorrhoea and genital chlamydial infection in a Somali village. Genitourin Med 1990;66:70-5.

13 Leclerc A, Frost E, Collet M, Goeman J, Bedjabaga L. Urogenital Chlamydia trachomatis in Gabon: an unrecognised epidemic. Genitourin Med 1988;64:308-11.

14 Blanding J Hirsch L Stranton N et al. Comparison of the Clearview Chlamydia, the PACE 2 assay, and culture for the detection of Chlamydia trachomatis and culture for the detection of Chlamydia trachomatis from cervical specimens in a low-pr.

15 Treharne JD, Darougar S, Simmons PD, Thin RN. Rapid diagnosis of chlamydial infection of the cervix. $\mathrm{Br} \mathcal{F}$ Venereal Diss 1978;54:403-8.

16 Puolakkainen $M$, Vesterinen E, Purola E, Saikku P, Paavonen P. Persistence of Chlamydial antibodies after pelvic inflammatory disease. f Clin Microbiol 1986;23: 924-8. 